\title{
Empreendedorismo étnico e de autoemprego em um olhar para as comunidades de imigrantes
}

\author{
Ethnic entrepreneurship and self-employment in a look at immigrant \\ communities
}

\section{Emprendimiento étnico y autoempleo en vista de las comunidades inmigrantes}

\author{
Laura Aparecida Santos Gomes ${ }^{1}$ \\ Cleonice Alexandre Le Bourlegat ${ }^{1}$
}

Recebido em 03/12/2018; revisado e aprovado em 31/10/2019; aceito em 30/01/2020

DOI: http://dx.doi.org/10.20435/inter.v21i2.2287

\begin{abstract}
Resumo: Este artigo tem como objetivo refletir a concepção de empreendedorismo étnico, quando esse se manifesta diante de desafios enfrentados por populações imigrantes recém-chegadas, como condição de autoemprego. Para isso, levantou-se um arcabouço teórico para a abordagem dos conceitos de empreendedor, suas concepções, motivações e atributos pessoais necessários, como também das motivações de necessidade e oportunidade que despertam a atividade empreendedora. Abordaram-se também os conceitos de etnia, etnicidade e formação da identidade como fator importante nas ações empreendedoras dos imigrantes. Posteriormente, sugerem-se pesquisas mais aprofundas nas comunidades de imigrantes a fim de identificar características que influenciem na atividade empreendedora, seja ela por necessidade em situações de vulnerabilidade, seja ela por oportunidade.
\end{abstract}

Palavras-chave: empreendedorismo; empreendedorismo étnico; autoemprego; imigrantes.

Abstract: This article aims to reflect the concept of ethnic entrepreneurship, when it manifests itself in the face of challenges faced by newly arrived immigrant populations, as a condition of self-employment. For this, a theoretical framework was raised to approach the concepts of the entrepreneur, their conceptions, motivations, and necessary personal attributes, as well as the motivations of need and opportunity that awaken the entrepreneurial activity. The concepts of ethnicity, ethnicity, and identity formation were also addressed, as an important factor in the entrepreneurial actions of immigrants. Subsequently, more in-depth researches in immigrant communities are suggested to identify characteristics that influence entrepreneurial activity, whether by necessity in situations of vulnerability or by opportunity.

Keywords: entrepreneurship; ethnic entrepreneurship; self-employment; immigrants.

Resumen: Este artículo tiene como objetivo reflejar el concepto de emprendimiento étnico, cuando se manifiesta ante los desafíos que enfrentan las poblaciones inmigrantes recién llegadas, como una condición de trabajo por cuenta propia. Para ello, se planteó un marco teórico para abordar los conceptos de emprendedor, sus concepciones, motivaciones y atributos personales necesarios, así como las motivaciones de necesidad y oportunidad que despiertan la actividad emprendedora. También se abordaron los conceptos de etnia, etnicidad y formación de identidad, como un factor importante en las acciones empresariales de los inmigrantes. Posteriormente, se sugieren investigaciones más profundas en las comunidades de inmigrantes para identificar las características que influyen en la actividad empresarial, ya sea por necesidad en situaciones de vulnerabilidad o por oportunidad.

Palabras clave: emprendedorismo; emprendedorismo étnico; trabajo por cuenta propia; inmigrante.

\section{INTRODUÇÃO}

O empreendedorismo, conceito que ganhou relevância nas condições do mundo atual, vem sendo construído, conforme bem lembram Hisrich e Peters (2004), desde a época de Marco Polo, em sua tentativa de estabelecer uma rota comercial com o Extremo Oriente. As mudanças dessa concepção foram sendo influenciadas no tempo, especialmente por meio de revoluções tecnológicas e sociais, conforme apontam Zen e Fracasso (2008). Segundo elas, assumir o risco em algo novo

\footnotetext{
${ }^{1}$ Universidade Católica Dom Bosco (UCDB), Campo Grande, Mato Grosso do Sul, Brasil.
} 
tem sido a característica comum do empresário nessa trajetória. No entanto as motivações, as barreiras e os desafios enfrentados pelo empreendedor têm sido alterados em cada situação.

Visto assim, as condições de necessidade enfrentadas pelos imigrantes que saem de seus territórios de origem na busca de novas oportunidades já acabam por induzir ações empreendedoras. Nesse caso, as barreiras culturais e de falta de determinadas credenciais exigidas, no momento de chegada a seus territórios de destino, podem ser detonadoras de uma forma de empreendedorismo de base étnica. Diante de barreiras para encontrar um emprego, conforme bem lembra Halter (2006), o grupo tende ao desafio de detectar nichos de mercado, nos quais os imigrantes possam atuar com certa vantagem. Nesse contexto, pode-se referir a um empreendedorismo de autoemprego.

Nesse processo, tem sido comum a constatação, durante o exercício do negócio empreendido, de um grande esforço para que os descendentes da "segunda geração se integrem na sociedade em posições vantajosas, independentemente de se dedicarem ou não aos negócios" (HALTER, 2006, p. 117). Desse modo, os padrões de empreendedorismo tendem a variar nas gerações seguintes.

O objetivo deste artigo é refletir a concepção do empreendedorismo étnico e de autoemprego no Brasil, procurando desvendar como ele se manifestou. Um dos objetivos específicos é verificar alguns aspectos desse empreendedorismo manifestado na chegada, que toma a forma de autoemprego, bem como identificar a forma criativa com que esses imigrantes recém-chegados combinam recursos culturais de origem, sob forma de conhecimentos e habilidades, com apoio da família e do grupo de origem, para garantir o sucesso de seus empreendimentos e a mobilidade social da geração futura. $\mathrm{O}$ artigo foi estruturado em três partes, além da introdução e das considerações finais. Na primeira, buscou-se trazer um referencial teórico que pudesse ajudar a compreender o surgimento do termo empreendedor. Em seguida, em segunda parte, abordaram-se os conceitos de empreendedorismo étnico e de autoemprego e de que forma eles se manifestam no contexto dos imigrantes. Buscaram-se conceitos de etnia e etnicidade, abordando também a construção da identidade do indivíduo em sua convivência social, assim como as representações culturais manifestadas e que influenciam nas suas ações e nos seus modos de vida. Tais aspectos são analisados no contexto do imigrante que busca empreender em um novo território por necessidade de subsistência e em situações de vulnerabilidade e que, posteriormente, pode tornar-se um empreendedor por oportunidade. A abordagem dos conceitos mostra a necessidade de pesquisas futuras com as populações de imigrantes, para que se possa compreender as nuances do empreendedorismo de autoemprego étnico.

\section{EMPREENDEDOR: CONCEPÇÕES E MOTIVAÇÕES}

\subsection{Concepções construídas a respeito do empreendedor como indivíduo}

O empreendedor da Idade Média, segundo Hisrich e Peters (2004), agia como um participante ou administrador de grandes projetos de obras, geralmente contratado pelo governo, que não corria riscos. Marco Polo, segundo os autores, teria sido um dos primeiros exemplos de empreendedor, no século XV, que passou a correr riscos. Ao estabelecer contrato com produtores de mercadorias, na condição de intermediário para realizar as vendas no Oriente, ele assumia os riscos emocionais e físicos da viagem. Para isso, o comerciante recebia um empréstimo a uma determinada taxa de juros, cabendo a ele uma percentagem dos lucros obtidos na venda. 
A Revolução Industrial promoveu mudanças estruturais na economia e na sociedade. Segundo Dornelas (2001), o termo entrepreneur, de origem francesa, para definir quem assume os riscos a começar algo novo, teria sido utilizado pela primeira vez pelo economista Richard Cantillon. Ele teria sido também um dos primeiros a diferenciar o empreendedor do capitalista, vendo o primeiro como quem assume riscos e o segundo como quem fornece o capital. Nesse novo contexto do século XVIII, dado pela Revolução Industrial e o pensamento iluminista, segundo Cantillon (1955), o empreendedor calculava de forma racional os riscos para enfrentar os desafios em um ambiente de incertezas, dado pela economia de mercado. No início do século XIX, Jean-Baptiste Say, economista francês adepto dos ideais iluministas e liberais, citado por Drucker (1987), apontou o empresário como o verdadeiro agente de mudanças, capaz de reunir os conhecimentos existentes para combiná-los com diferentes meios de produção, na criação de seu novo empreendimento.

Na primeira metade do século XX, em plena vigência da Segunda Revolução Industrial, quando novas mudanças estruturais haviam ocorrido, seguidamente da crise do sistema capitalista industrial dos anos 1930, o economista Joseph Alois Schumpeter (1985) teorizou a respeito da figura do empresário, diferenciando-o do capitalista. Baseado nos princípios da teoria do sistema de equilíbrio econômico, pregava que as mudanças econômicas exerciam um papel adaptativo, visando manter esse sistema em equilíbrio. Para ele, as mudanças revolucionárias que exerciam esse papel emergiam de dentro do sistema. Todo ato concreto de produção envolveria certa combinação econômica e tecnológica. Se produzir significa combinar matérias e forças ao alcance do capitalista, um novo empreendimento significava novas combinações propostas pelo empresário. A inovação é definida exatamente por essas combinações que dão origem ao novo empreendimento. O empresário seria, para ele, esse sujeito capaz de criar essas novas possibilidades, realizando combinações novas com os fatores produtivos. O empresário inovador, visto como agente central dos processos de mudança socioeconômica, foi considerado por ele um tipo especial, portanto privilégio de um pequeno número de pessoas. Para Filion (1991), o empreendedor constrói uma visão de futuro e desenvolve os devidos esforços para concretizá-la.

A partir dos anos 90 do século XX, quando o mundo se mostrou conectado em rede mediante o suporte das tecnologias de informação e comunicação, passou-se a exigir uma visão e práticas sistêmicas. A instabilidade desse mundo sistêmico com preponderância da velocidade de ações exigiu maior autonomia socioeconômica local e regional. Algumas teorias de inovação mais conhecidas desse período foram elaboradas pelos economistas evolucionistas neoschumpeterianos (Richard Nelson, Sidney Winter, Bengt-Åke Lundvall, Chris Freeman e Giovanni Dosi), complementadas por outros pensadores da área socioeconômica. Essas se diferenciaram das teorias anteriores. Nesse caso, não envolviam apenas a empresa capitalista, mas um conjunto daquelas que atuam no mesmo ramo, em parceria com outras organizações e o governo, como também a sociedade civil organizada. Trata-se de uma abordagem sistêmica da inovação, que se apoia em uma aprendizagem coletiva entre as partes interessadas. Essas iniciativas coletivas empreendedoras geram "meios inovadores", "ecossistemas de inovação", "ambientes de inovação", "territórios inteligentes", entre outras concepções de abordagem territorial.

No contexto comportamental, os adeptos da teoria comportamentalista focalizam o empreendedor a partir de seus atributos, em um esforço de identificar e explicar o perfil de quem é motivado a empreender. Para eles, o empreendedor é concebido a partir de um conjunto de atributos pessoais e psicológicos. 
Max Weber (1981), na sociologia, viu os empreendedores como indivíduos inovadores, independentes, com papel de liderança e autoridade nos negócios. Tentou correlacionar esses talentos com determinadas peculiaridades mentais e espirituais que os sujeitos adquiriam no seu ambiente de vida, durante seu processo educativo. Essas características mentais e espirituais dos empreendedores decorriam, sobretudo, da educação que vinham recebendo. Esta era favorecida especialmente pela atmosfera religiosa da família e do lar, que acabava por determinar a escolha da ocupação e da carreira. Desse modo, para esse autor, o sistema de valores era visto como um elemento fundamental para a explicação do comportamento empreendedor. Para compreender esse comportamento, Weber (1981) buscou relacionar a afiliação religiosa com a estratificação social na região do Vale do Ruhr, na Alemanha, durante a industrialização manifestada no século XIX. Ele concluiu que os filhos de católicos tendiam a ser mais induzidos a seguir carreiras profissionais nas ciências humanas. Em contraponto, os protestantes seguiam carreiras técnicas e destacavam-se como dirigentes nas indústrias. Weber (2002) verificou que alguns ramos do protestantismo, devido aos preceitos de sua fé e da ética proferidas, deram contribuição relevante para a formação do espírito que impulsiona a economia ocidental moderna. Desse modo, ao analisar o empreendedor envolvido com os processos de inovação na indústria, em um enfrentamento às instituições tradicionais de base agrária, o autor atribuiu um conjunto de talentos. Esse empreendedor demonstrava um novo estilo caracterizado por uma extraordinária firmeza de caráter, clarividência e capacidade de ação. Seriam esses atributos que permitiam que ele conquistasse a confiança de seus clientes e operários.

Já o psicólogo David McClelland (1972) complementou Weber (1981) quando procurou identificar as características psicológicas de um empreendedor, fundamentadas em três naturezas de necessidades: (1) necessidade de realização, ao se buscar a superação de seus limites, realizando algo melhor do que vinha fazendo; (2) necessidade de se integrar a um determinado grupo social; (3) necessidade de controlar o ambiente, influenciando ou dirigindo o comportamento dos outros. Diante dessa natureza de necessidades, o empreendedor deveria ser dotado das seguintes características ou talentos: iniciativa, visão, coragem, firmeza, decisão, atitude de respeito humano, capacidade de organização e direção.

Também Dolabela (2003), ao conceber a ação de empreender como construção de um futuro, valorizou as características mentais e espirituais de quem empreende:

Empreender é um processo humano, com toda a carga que isso representa: ações dominadas por emoção, desejos, sonhos, valores, ousadia de enfrentar as incertezas e de construir a partir da ambiguidade e no indefinido; consciência da inevitabilidade do erro em caminhos não percorridos; rebeldia e inconformismo; crença na capacidade de mudar o mundo; indignação diante de iniquidades sociais. (DOLABELA, 2003. p. 29)

Para esse autor, outro atributo do empreendedor consiste em sua capacidade criativa e de cooperação a partir de recursos escassos ou inexistentes. No final do século XX, os avanços dos processos produtivos, a valorização e a disseminação conhecimento nas empresas trouxeram uma nova concepção dos profissionais criativos e inovadores, com capacidade para trabalhar de forma autônoma ou em pequenas produções (DOLABELA, 2003).

De todo modo, Fillion (1988) aludiu a uma certa confusão reinante nessa concepção de empreendedor, após a contribuição de outros autores não economistas. Segundo ele, ainda que falte consenso, esse conceito vem ganhando expressão na atualidade. 
Na década de 70 do século XX, período do Pós-Guerra e início da segunda crise do sistema capitalista industrial, Peter Drucker (1987) passou a defender a ideia de que o perfil do empreendedor não se limitava apenas aos talentos pessoais para empreender, mas era preciso saber aproveitar oportunidades para criar mudanças.

O programa de pesquisa Global Entrepreneurship Monitor (GEM), de abrangência mundial, teve início em 1999, em uma parceria de vários países com a London Business School, da Inglaterra, e o Babson College, dos Estados Unidos. Consiste em uma avaliação anual das atividades empreendedoras dos países, sendo considerado um dos estudos mais contínuos sobre a dinâmica empreendedora e que possibilita comparações globais. De acordo com pesquisas atuais realizadas pela GEM (2011, p. 89), existem aqueles que empreendem por necessidade e outros por oportunidade. Na primeira categoria, estão aqueles que não possuem opções de trabalho e visam ao sustento próprio e/ou da família. A dificuldade em que se encontra um determinado indivíduo acaba por motivá-lo a empreender, submetendo-se a determinadas situações, mesmo não estando devidamente preparado para enfrentá-las. Já o empreendedorismo por oportunidade manifesta-se quando o indivíduo consegue detectar chances diante de uma oportunidade de mercado e se encontra mais bem preparado para planejar suas ações, portanto, tem chances de escolha.

No entanto Julien (2010) alerta para a necessidade de se reconhecer que, por mais que o empreendedor apresente qualidades individuais, ele é um ser social. Na complexidade relacional do ambiente socioeconômico do território em que cada empreendedor se manifesta, ele não depende apenas de suas qualidades pessoais. É preciso verificar que ele também depende das oportunidades e limitações dadas por esse meio socioeconômico em termos de recursos, sejam eles materiais, sejam eles imateriais. Tanto os recursos do meio como a cultura empreendedora que dele faz parte são fundamentais para dinamizar o empreendedorismo local, assim como o empreendedorismo é fundamental para dinamizar o meio.

Também, Castillo-Palacio, Batista-Canino e Zuñiga-Collazos (2017) concebem o empreendedorismo como um fenômeno sistêmico, que precisa ser mais bem compreendido no ambiente de relações em que se manifesta. Segundo eles, entre as diversas variáveis que concorrem para que esse ambiente possa contribuir para estimular ou limitar o empreendedorismo, está a cultura, considerada elemento-chave para a criação do negócio.

\section{EMPREENDEDORISMO DE AUTOEMPREGO E ÉTNICO}

Para Dolabela (1999, p. 29), o termo empreendedorismo é uma livre tradução que se faz da palavra entrepreneurship, designando uma área de grande abrangência e que trata de outros temas além da criação de empresas: (1) geração de autoemprego (trabalhador autônomo); (2) empreendedorismo comunitário (como as comunidades empreendem); (3) intraempreendedorismo (o empregado empreendedor); (4) políticas públicas (políticas governamentais para o setor). Nesse sentido, o empreendedorismo pode contemplar várias dinâmicas de práticas empreendedoras, entre elas, pode-se destacar o empreendedorismo de autoemprego e o empreendedorismo étnico.

Vários estudiosos promoveram embates teóricos acerca do empreendedorismo de autoemprego. Observa-se que sua mola propulsora pode advir de momentos de crise econômica e social, gerada por diversos fatores que afetam o emprego formal. Desta forma, a situação 
de necessidade faz com que o indivíduo crie novas formas de subsistência baseadas em seus conhecimentos e saberes adquiridos no decorrer de sua vida, desenvolvendo novas formas de trabalho independente. A autonomia e o controle do processo produtivo foram também considerados características básicas para a definição de autoemprego (PAMPLONA, 2001; PARKER, 2004; BURCHELL; DEAKIN; HONEY, 1999).

Perulli (2003) usa o termo autoempregado para o trabalhador independente, já Parker (2004) complementa o conceito quando se refere à renda do trabalhador autoempregado, sujeita aos riscos e à volatilidade das receitas, diferentemente do assalariado, por este contar com renda pré-fixada e proteção da Legislação Trabalhista. Desta forma, pode-se depreender que o autoemprego objetiva o sustento do próprio indivíduo que detém a força de trabalho, os meios de produção e o conhecimento. O autoempregado trabalha de forma autônoma, assumindo riscos e tendo uma remuneração de acordo com seu próprio esforço.

Baseando-se nas colocações desses autores, pode-se afirmar que o empreendedorismo de autoemprego manifesta-se em situação de necessidade, como um trabalho autônomo e independente, voltado ao próprio sustento. Esse tipo de empreendedor é detentor, ao mesmo tempo, do conhecimento, da força de trabalho e dos meios de produção, assumindo os riscos inerentes ao seu negócio.

O empreendedorismo étnico, de acordo com Waldinger, Aldrich e Ward (1990, p. 13), diz respeito a um "um conjunto de conexões e padrões regulares de interação entre pessoas que compartilham experiências nacionais comuns ou de migração". Esse fenômeno interativo tem como base o grupo étnico, pensado como um grupo que tem origem e compartilha uma cultura comum, como um segmento da sociedade.

Mas essa concepção de empreendedorismo étnico sofreu evoluções teóricas, especialmente nos EUA, onde essa manifestação foi significativa e apresenta longa história. Uma das teorias que ganharam expressão posterior nesse país prega que as empresas étnicas aparecem como uma reação óbvia diante de oportunidades bloqueadas no mercado de trabalho (VOLERY, 2007). De fato, os imigrantes que chegaram no século XIX aos EUA enfrentaram barreiras linguísticas e de reconhecimento de sua escolaridade no país de destino, ficando à margem do mercado de trabalho formal. Por outro lado, segundo Fregetto (2004), a pobreza, a discriminação e o conhecimento limitado da cultura local dificultaram sua mobilidade social. Desse modo, os imigrantes se inseriram inicialmente no país como mão de obra temporária, em empregos que não exigiam grandes habilidades (WALDINGER; ALDRICH; WARD, 1990). Esses fatores estruturais no ambiente hospedeiro exerceram influência, especialmente diante da discriminação e das barreiras de entrada no mercado de trabalho, induzindo ao "autoemprego". Assim, aqueles que não têm chance de se enquadrar como empregados são obrigados a se estabelecer por conta própria. Os primeiros empreendimentos criados, via de regra, significam uma forma de autoemprego que possa garantir a sobrevivência no território de destino. Trata-se de uma forma de empreendedorismo motivado pela "necessidade". Com o passar do tempo, depois de estabelecidos, esses passam a mudar de condição, montando as chamadas "empresas étnicas". Desse modo, nos EUA, já entre 1820 e 1830, ocorria a ampla expansão dos pequenos negócios. Em 2005, a taxa de empreendedorismo dos imigrantes era cerca de 0,35\%, contra 0,28\% dos americanos natos (HALTER, 2006). Um bom exemplo é a participação das minorias raciais e étnicas em algumas atividades econômicas, como coreanos em quitandas, chineses em lavanderias, judeus em indústrias e confecções. 
Outro fator importante são as oportunidades oferecidas no contexto de um território de acolhimento de imigrantes, as quais, segundo Razin e Collins (1999), exercem forte influência na forma de eles se inserirem no território e poderem ascender em sua mobilidade social. Kloosterman, Van Der Leun e Rath (1999) lembram que, para poderem avançar e se tornarem competitivos, os condutores de negócios étnicos acabam sendo tentados a se utilizarem de práticas informais, que os livrem de impostos, regulamentos trabalhistas, salários mínimos (KLOOSTERMAN; VAN DER LEUN; RATH, 1999). Desse modo, os negócios alavancados para a sobrevivência ocorrem com base em uma dinâmica de cooperação entre compatriotas, constituindo-se, assim, em um nicho étnico. Os imigrantes recém-chegados, desse modo, tendem a ser treinados de forma prática pelos mais antigos, favorecendo a mobilidade social. O empreendedorismo de autoemprego avaliado nas experiências dos imigrantes que afluíram para os EUA não trouxe sinal de sucesso, mas representou uma alternativa para o desemprego (VOLERY, 2007).

Os adeptos da teoria cultural, de acordo com Masurel, Nijkamp e Vindigni (2004), defendem o pressuposto de que os imigrantes, diante da situação difícil que enfrentam no país de destino, acabam adotando determinadas características comportamentais, tais como a dedicação ao trabalho mesmo que árduo, o sentimento de pertença ao seu grupo étnico, a aceitação do risco, o respeito aos seus valores sociais, a solidariedade. Para Fregetto (2004), essas características representam um recurso étnico, que os ajudam e induzem o empreendedorismo. Essa situação de discriminação e dificuldade no ato de chegada, segundo Jones e McEvoy (1986), favorece a manifestação da consciência de sua identidade cultural de origem. Ela ajuda o imigrante a tomar consciência também das vantagens que a sua própria cultura pode lhes oferecer no novo ambiente de vida.

Depois de um determinado tempo, as empresas do grupo étnico começam a se desenvolver, obtendo aceitação social, tornando-se um negócio viável, em função de uma complexidade de relações estabelecidas no território. Conforme aponta Volery (2007), as dinâmicas impulsionadas pelas estratégias étnicas para alcançar o sucesso nos empreendimentos dependem, de um lado, da estrutura de oportunidades existentes no ambiente do território que o imigrante elegeu para viver e, de outro, de seus próprios recursos étnicos. A estrutura de oportunidades no território de destino, segundo Waldinger, Aldrich e Ward (1990), é composta pelas condições de mercado (nicho de mercado, mercado aberto), pelo acesso à propriedade, pelas condições oferecidas pelo mercado de trabalho e pelo quadro jurídico e institucional. Os principais recursos étnicos são constituídos por suas tradições culturais e pelas redes sociais étnicas. As dinâmicas ocorrem por meio de estratégias étnicas estabelecidas na interação complexa entre as estruturas de oportunidade e os recursos étnicos do grupo herdados e construídos no lugar. Nesse segundo momento, ele já se encontra mais preparado para planejar suas ações.

Os estudos mais abrangentes sobre cultura apontam que as influências culturais nos empreendimentos são fator preponderante para o sucesso do negócio, pois a cultura delineia o comportamento empreendedor. Hofstede (2001) ajudou a demonstrar de forma mais clara as diferenças entre os países para explicar as tendências comportamentais empresariais dos indivíduos, apreciadas em cinco dimensões. A primeira delas diz respeito à característica cultural relacionada ao risco e à incerteza, ou seja, no momento que indivíduos se sentem ameaçados em relação à incerteza, podem apresentar maior ou menor nível de prevenção para enfrentála. A segunda refere-se à predominância da cultura do individualismo ou do coletivismo na 
sociedade. Em sociedades individualistas, próprias de sociedades nas quais as conexões ainda são fracas, prevalece o sentido de independência, valores e objetivos individuais. Já nas sociedades coletivistas, em que as pessoas apresentam fortes conexões, prevalecem os valores e objetivos coletivos. A terceira dimensão diz respeito à "distância do poder". Quando a distância do poder é baixa, manifestam-se indivíduos mais independentes, menores desigualdades sociais, direitos iguais. Quando essa distância é alta, os indivíduos se tornam mais interdependentes, enquanto os maiores privilégios são dados a quem tem poder. A quarta dimensão relaciona-se com masculinidade-feminilidade. Nas sociedades em que são atribuídas maior importância aos valores masculinos, as pessoas se concentram mais no trabalho, prevalecendo valores ligados ao sucesso, competição e desempenho. Nas sociedades em que os valores femininos são importantes, destacam-se mais valores como igualdade, solidariedade e harmonia social. A quinta dimensão é dada pela cultura da orientação em longo e curto prazo. Nas culturas que tendem para a orientação em longo prazo, predominam os valores como determinação, prudência, sentimento de vergonha, regulação das relações com base em status e adaptabilidade individual. Nas culturas em que predomina a orientação em curto prazo, os valores fundamentais passam a ser a estabilidade individual, o respeito à tradição e a negligência do status nas relações sociais.

\subsection{Identidade étnica e etnicidade}

A identidade não é algo singular de um grupo ou resultado, mas um processo que se constrói socialmente (HALL, 2006). Para Cuche (2002), a identidade se constrói, de fato, na convivência em sociedade, sendo reafirmada diante da relação mantida com o outro. Esse outro pode ser representado tanto por grupos vizinhos da mesma sociedade quanto de outra. Nesse processo, cada grupo ou sociedade constrói uma representação de si mesma, o que vem a constituir sua identidade social, que envolve um constante desafio para se afirmar internamente (MAFFESOLI, 1998).

O processo de construção da identidade, segundo Hall (2006), leva em conta um conjunto de representações culturais, construídas em situações específicas, em um "modo de construir sentidos que influencia e organiza tanto nossas ações quanto a concepção que temos de nós mesmos (HALL, 2006). Portanto, conforme afirma Silva (2000), a construção da identidade vem sempre associada ao conceito de cultura, o que ajuda a compreender o conceito de identidade étnica. Os indicadores de envolvimento étnico mais comuns são: língua, amizade, organizações sociais, religião, tradições culturais e política (PHINNEY, 1990).

De acordo com Poutignat e Streiff (1998), a identidade étnica se manifesta sob forma de uma consciência de pertença ao grupo, em função de suas características socioculturais, sendo construída na relação com outros grupos. Assim, ela se constrói em um processo de diferenciação cultural.

A identidade étnica (a crença na vida comum étnica) constrói-se a partir da diferença. Atração entre aqueles que se sentem como uma mesma espécie e indissociável da repulsa diante daqueles que são percebidos como estrangeiros. Esta ideia implica que não é o isolamento que cria a consciência de pertença, mas, ao contrário, a comunicação das diferenças das quais os indivíduos se apropriam para estabelecer fronteiras étnicas. (POUTIGNAT; STREIFF, 1998, p. 40)

Além de estabelecer limites para o grupo, a identidade étnica ajuda a reforçar sua solidariedade, em uma dicotomização da diferenciação entre o "nós" e "eles" (BARTH apud 
POUTIGNAT; STREIFF-FERNART, 1998). A intensificação desse sentimento de pertença a um dado grupo étnico, de acordo com Phinney (2004), ocorre diante da presença de seu grupo ou comunidade como também da participação ativa na cultura construída, ou ainda por meio dos esforços paternos em sua manutenção junto às gerações futuras.

A oportunidade de participar de festivais étnicos, de desfrutar de grupo de dança étnico, de obter comida étnica nos mercados e restaurantes e de conhecer-se e casar-se com coétnicos pode ser fator que intensifica os sentimentos de pertencimento a uma etnia e atitudes étnicas positivas. A presença (ou ausência) de uma comunidade étnica é um fator de grande poder para a identidade étnica de um indivíduo. Além da estrutura da comunidade, os esforços dos pais para manter sua cultura são importantes fatores determinantes para a identidade étnica (PHINNEY, 2004, p. 57-8).

A etnicidade, por seu turno, expressa a forma em que se manifesta a identidade étnica, diferenciando-a de outras etnias. Ela manifesta o caráter do grupo étnico (GLAZER; MOYNIHAN; SCHELLING, 1975), em torno de interesses comuns (COHEN, 1974), sendo validada pelos signos culturais que diferenciam esse grupo de outro na sociedade (BARTH apud POUTIGNAT; STREIFFFERNART, 1998). A etnicidade é uma forma de qualificação do grupo étnico, que se expressa em um processo relacional, uma vez que está em contínua construção no contexto das relações sociais.

Visto assim, pode-se deduzir que todo grupo imigrante manifesta sua identidade étnica ao se relacionar com aqueles que não fazem parte desse grupo e, nesse processo, manifesta sua etnicidade. Desse modo, conforme lembra Phinney et al. (2002), os indivíduos e grupos imigrantes sempre chegam a um novo país com atitudes diferenciadas. Mesmo que assimilem características da nova cultura, a tendência é a de replicar os costumes e tradições aos seus herdeiros nascidos no novo país. O envolvimento na vida social e nas práticas culturais do grupo étnico indica a tendência da afirmação de sua identidade étnica.

As condições de necessidade enfrentadas pelos imigrantes que saem de seus territórios de origem na busca de novas oportunidades são suficientes para induzir ações empreendedoras. As barreiras culturais no território de destino e a falta de determinadas credenciais exigidas, no momento de chegada, podem ser detonadoras de uma forma de empreendedorismo de base étnica.

Conforme assinala Nwankwo (2005), o empreendedorismo de autoemprego tem sido mais comum entre imigrantes/minorias étnicas que sofrem restrições no mercado de trabalho no país de residência. A mola propulsora dessa natureza de empreendedorismo, conforme Freire (1994), passa a ser a crise ou a barreira de entrada ao emprego formal no mercado. 0 empreendedorismo de autoemprego, nesse caso, manifesta-se em situação de necessidade, para ser desenvolvido como uma forma de trabalho independente (FREIRE, 1994). Nos EUA, diante da longa história de oportunidades bloqueadas no mercado de trabalho a imigrantes, a manifestação do empreendedorismo de autoemprego tem sido marcante (VOLERY, 2007). Os imigrantes que chegaram aos EUA no século XIX, segundo Waldinger, Alddrich e Ward (1990), enfrentaram barreiras linguísticas e de reconhecimento de sua escolaridade no país de destino, ficando à margem do mercado de trabalho formal. Os imigrantes se inseriram inicialmente no país como mão de obra temporária, em empregos que não exigiam grandes habilidades (WALDINGER; ALDDRICH; WARD, 1990).

A autonomia e o controle do processo produtivo foram considerados características básicas para a definição de autoemprego (PAMPLONA, 2001; PARKER, 2004; BURCHELL; DEAKIN; HONEY, 1999). Trata-se de uma situação em que o empreendedor se torna proprietário do trabalho e dos 
meios de produção, o que Ihe atribui maior autonomia de trabalho e flexibilidade de horários. No entanto o autoempregado fica mais sujeito aos riscos e à volatilidade das receitas do que um assalariado, que conta com renda pré-fixada e proteção da Legislação Trabalhista (PARKER, 2004).

Diante de barreiras para encontrar um emprego, conforme bem lembra Halter (2006), o grupo tende ao desafio de detectar nichos de mercado nos quais possa atuar com certa vantagem. Nesse contexto, pode-se referir a um empreendedorismo de autoemprego. Nessas condições, nos negócios alavancados para a sobrevivência, tende a se manifestar uma dinâmica de cooperação entre compatriotas, constituindo-se em um nicho étnico. Com o passar do tempo, depois de estabelecidos, esses passaram a mudar de condição, montando as chamadas "empresas étnicas". O empreendedorismo étnico revela-se, nesse caso, como "um conjunto de conexões e padrões regulares de interação entre pessoas que compartilham experiências nacionais comuns ou de migração" (WALDINGER; ALDDRICH; WARD, 1990, p. 3). Esse fenômeno interativo tem como base o grupo étnico, que tem origem e compartilha uma cultura comum, como um segmento da sociedade.

\subsection{Empreendedorismo étnico por oportunidade}

Depois de um determinado tempo, as empresas de um grupo étnico podem se desenvolver, tornando-se um negócio viável, com maior aceitação social, em função da complexidade de relações que vão sendo estabelecidas no território ao longo do tempo. O empreendedorismo étnico tende a se apresentar, portanto, durante a fase de chegada ao território de destino, sempre como opção de empreendedorismo de autoemprego e, em um segundo momento, podendo avançar como negócio étnico próspero.

Conforme assinala Reynolds (2005), as oportunidades detectadas pelo empreendedor suscitam dele um novo esforço de criação e organização. Nesse sentido, Volery (2007) alerta que as dinâmicas impulsionadas pelas estratégias étnicas para alcançar o sucesso nos empreendimentos dependem, de um lado, da estrutura de oportunidades existentes no ambiente do território que o imigrante elegeu para viver, mas, de outro, de seus próprios recursos étnicos para poder criar e se organizar.

A estrutura de oportunidades no território de destino, segundo Waldinger, Mcevoy e Aldrich (1990), é composta pelas condições de mercado (nicho de mercado, mercado aberto), pelo acesso à propriedade, pelas condições oferecidas pelo mercado de trabalho e pelo quadro jurídico e institucional. Já os recursos étnicos são constituídos pelas tradições culturais e pelas redes sociais étnicas. As dinâmicas ocorrem por meio de estratégias étnicas, estabelecidas em uma interação complexa entre as estruturas de oportunidade e os recursos étnicos do grupo.

De acordo com Halter (2006), no empreendedorismo étnico, são as características culturais distintivas da etnia que contribuem para o sucesso do empreendimento. Nesse caso, a etnia se transforma num fator do desenvolvimento do empreendimento, que se revela como etnicidade, com práticas estratégicas que podem envolver a contratação de patrícios, negócios com clientes étnicos, criação de formas étnicas de capitalização de fundos financeiros, entre outros.

O conhecimento que se constrói no empreendedorismo étnico, segundo Halter (2006), geralmente não é obtido por vias acadêmicas. As competências, via de regra, são construídas na própria trajetória do negócio e em algumas ocasiões em que os governos de países de destino oferecem alguma forma de treinamento. Para essa autora, o empreendimento étnico muitas vezes chega a servir de escola para futuros empreendedores. Desse modo, não é incomum que 
pessoas de mesma etnia que se empregam nesses empreendimentos étnicos acabem tendo maiores chances de virem a construir o próprio negócio.

Os filhos de empreendedores étnicos podem crescer e assumir o negócio da família, embora isso não aconteça obrigatoriamente. Neste processo, tem sido comum a constatação, durante o exercício do negócio empreendido, de um grande esforço para que os descendentes da "segunda geração se integrem na sociedade em posições vantajosas, independentemente de se dedicarem ou não aos negócios" (HALTER, 2006, p. 117). Desse modo, os padrões de empreendedorismo tendem a variar nas gerações seguintes.

\section{CONSIDERAÇÕES FINAIS}

A presente pesquisa teve o objetivo de buscar as bases teóricas do empreendedorismo e as novas vertentes ainda em estudo, em que se destacam o empreendedorismo étnico e o de autoemprego, com o intuito de elucidar e compreender tais fenômenos. Pode-se então observar o surgimento do termo empreendedor e em que condições isso ocorreu no contexto da constituição de negócios. Posteriormente, foram analisados os conceitos de empreendedorismo, com foco no empreendedorismo de autoemprego étnico que é observado nas práticas empreendedoras das populações de imigrantes, e de que forma ele ocorre.

Depreendeu-se das teorias que o empreendedorismo étnico tende a se apresentar, durante a fase de chegada ao território de destino, como opção de empreendedorismo de autoemprego, podendo avançar posteriormente para um negócio étnico próspero.

$O$ ato de empreender em um primeiro momento é regido por motivações de necessidade e, em um segundo momento, por motivações de oportunidades. O comportamento do imigrante é fator preponderante no desenvolvimento de ações empreendedoras, pois o imigrante enfrenta muitas adversidades na chegada e no seu período de adaptação ao novo território. Weber (2002) trouxe pontos importantes a serem estudados nas ações empreendedoras de imigrantes: (1) necessidade de realização, ao se buscar a superação de seus limites, realizando algo melhor do que vinha fazendo (2) necessidade de se integrar a um determinado grupo social (3) necessidade de controlar o ambiente, influenciando ou dirigindo o comportamento dos outros.

O empreendedorismo do imigrante pode variar de acordo com as características do território que o recebe, o que será fator determinante à forma de empreender. Para os autores, o imigrante, ao chegar ao novo território, depara-se, em um primeiro momento, com poucas opções oferecidas para trabalho e subsistência; dessa forma, o indivíduo se sente menos preparado para enfrentar o mercado de trabalho local. Essa situação o expõe a um empreendedorismo de autoemprego por necessidade de subsistência.

Há de se destacar que os recursos tradicionais são tidos como diferenciais inerentes aos imigrantes na hora de empreender. Ao chegar no novo território, o imigrante enfrenta diversas barreiras, entre elas a linguagem, discriminação etnocêntrica, além da adaptação à organização social do território de destino.

O segundo momento ocorre quando o empreendedor étnico consegue identificar chances na estrutura de oportunidades e, com base nos seus próprios recursos, cria negócios para a atender às necessidades das pessoas do local. Esse fato faz surgir novos empreendimentos em atividades diferentes àquelas do momento de chegada. As condições do território de acolhimento também são fatores preponderantes no desenvolvimento dos empreendimentos de autoemprego 
étnicos; nesse contexto, é importante que se realizem estudos futuros com as populações de imigrantes empreendedores de etnias diversas, no intuito de identificar características culturais de cada etnia e suas especificidades que influenciam nas táticas e estratégias empreendedoras.

\section{REFERÊNCIAS}

BARTH, F. Os grupos étnicos e suas fronteiras. In: O guru, o iniciador e outras variações antropológicas. Rio de Janeiro: Contra Capa Livraria, 2000.

BURCHELL, B.; DEAKIN, S.; HONEY, S. The employment status of individuals in non-standard employment. Londres: British Departament of Trade and Industry, 1999.

CANTILLON, R. Essai sur la nature du commerce en général. [S.I.]: Routledge, 1955.

CASTILLO-PALACIO, M.; BATISTA-CANINO, R.; ZUÑIGA-COLLAZOS, A. The relationship between culture and entrepreneurship: from cultural dimensions of GLOBE Project. Revista Espacios, v. 38, n. 34, p. 12-25, 2017. COHEN, A. The lesson of ethnicity. In: COHEN, A. Urban ethnicity. Londres: Tavistock, 1974.

CUCHE, Denys. O conceito de cultura nas ciências sociais. Tradução de Viviane Ribeiro. 2 ed. Bauru: EDUSC, 2002.

DOLABELA, F. Pedagogia empreendedora. São Paulo: Cultura, 2003.

DOLABELA, F. Oficina do empreendedor: a metodologia de ensino que ajuda a transformar conhecimento em riqueza. São Paulo: Cultura, 1999.

DORNELAS, J. C. A. Empreendedorismo: transformando ideias em negócios. Rio de Janeiro: Elsevier, 2001.

DRUCKER, P. F. Inovação e espírito empreendedor. São Paulo: Pioneira, 1987.

FILLION, L. J. O planejamento do seu sistema de aprendizagem empresarial: identifique uma visão e avalie o seu sistema de relações. RAE - Revista de Administração de Empresas, São Paulo, v. 31, n. 3, p. 63-71, jul./set. 1991.

FILLION, L. J. The strategy of successful entrepreneurs in small business: vision, relationships and anticipatory learning. 1988. Thesis (Ph.D.) - University of Lancaster Great Britain (UMI 8919064), Lancaster, 1988. 2v.

FREGETTO, E. Immigrant and ethnic entrepreneurship: a U.S. perspective. In: WELSCH, H. P. (Ed.). Entrepreneurship: the way ahead. New York: Routledge, 2004. p. 253-68.

FREIRE, J. O auto-emprego: alguns comentários sobre os dados recentes. Revista Crítica de Ciências Sociais, Coimbra, Portugal, n. 40, p. 137-51, 1994.

GLAZER, N.; MOYNIHAN, D. P.; SCHELLING, C. S. Ethnicity: theory and experience. Cambridge: Harvard University, 1975

GLOBAL ENTREPRENEURSHIP MONITOR (GEM). Empreendedorismo no Brasil. Curitiba: IBQP, 2011. Disponível em: http://ibqp.org.br/wp-content/uploads/2016/10/Empreendedorismo-no-Brasil-2011. pdf. Acesso em: 5 mar. 2018.

HALL, S. A identidade cultural na pós-modernidade. Rio de Janeiro: Dp\&A, 2006.

HISRICH, R. D.; PETERS, M. P. Empreendedorismo. 5. ed. Porto Alegre: Bookman, 2004. 
HOFSTEDE, G. Culture's consequences: comparing values, behaviors, institutions, and organizations across nations. 2. ed.). Thousand Oaks: Sage Publications, 2001.

JONES, T.; McEVOY, D. Ethnic enterprise, the popular image. In: CURRAN, J.; STANWORTH, J.; WATKINS, D. (Ed.). The survival of the small firm. Aldershot: Gower, 1986.

JULIEN, P.-A. Empreendedorismo regional e economia do conhecimento. São Paulo: Saraiva, 2010.

KLOOSTERMAN, R.; VAN DER LEUN, J.; RATH, J. Mixed embeddedness: (in)formal economic activities and immigrant businesses in the Netherlands. International Journal of Urban and Regional Research, $\mathrm{v}$. 23, n. 2, p. 253-67, jun. 1999.

MAFFESOLI, M. Elogio da razão sensível. Petrópolis, RJ: Vozes, 1998.

MASUREL, E.; NIJKAMP, P.; VINDIGNI, G. Breeding places for ethnic entrepreneurs: a comparative marketing approach. Entrepreneurship \& Regional Development, n. 16, p. 77-86, 2004.

MCCLELLAND, D. C. A sociedade competitiva: realização e progresso social. Tradução de Álvaro Cabral. Rio de Janeiro: Expressão e Cultura, 1972.

NWANKWO, S. Characterisation of black african entrepreneurship in the UK: a pilot study. Journal of Small Business and Entreprise Development, v. 12, n. 1, p. 120-37, 2005.

PAMPLONA, J. B. Erguendo-se pelos próprios cabelos: autoemprego e reestruturação produtiva no Brasil. São Paulo: Germinal: FAPESP, 2001.

PARKER, S. C. The economics of self-employment and entrepreneurship. Cambridge: Cambridge University Press, 2004.

PERULLI, A. Economically dependent / quasi-subordinate (parasubordinate) employment: legal, social and economic aspects. Paris: European Commission, Committee for Employment and Social Affairs, 2003.

PHINNEY, J. S. Ethnic identity: development and contextual perspectives. In: CONGRESSO CULTURE \& DIVERSITY IN PSYCHOLOGY AND EDUCATION, 2004. Disponível em: http://citeseerx.ist.psu.edu/viewdoc/ download?doi=10.1.1.477.1331\&rep=rep1\&type=pdf . Acesso em: 22 jul. 2018.

PHINNEY, J. S. Ethnic identity in adolescence and adulthood. Psychological Bulletin, n. 108, p. 499-514, 1990.

PHINNEY, J. S.; HORENKZIK, G.; LIEBKIND, K.; VEDDER, P. Ethnic identity, immigration, and well-being: an interactional perspective. Journal of Social Issues, v. 57, n. 3, p. 493-510, set. 2002.

POUTIGNAT, P.; STREIFF-FERNART, J. Teorias da etnicidade seguidos de grupos étnicos e suas fronteiras de Fredrick Barth. Tradução Elcio Fernandes. São Paulo: Unesp, 1998

RAZIN, O.; COLLINS, S. M. Real exchange-rate misalignments and growth. In: RAZIN, A.; SADKA, E. (Ed.). The economics of globalization: policy perspectives from public economics. Cambridge: Cambridge University Press, 1999.

REYNOLDS, P. D. Understanding business creation: serendipity and scope in two decades of business creation studies. Small Business Economics, v. 24, n. 4, p. 359-64, 2005.

SAY, Jean Baptiste. Tratado de economia política. Prefácio de Georges Tapinos. São Paulo: Abril Cultural, 1983. (Coleção Os Economistas). 
SCHUMPETER, J. O fenômeno fundamental do desenvolvimento econômico. In: SCHUMPETER, J. A Teoria do Desenvolvimento Econômico. Rio de Janeiro: Nova Cultural, 1985.

SILVA, T. T. A produção social da identidade e da diferença. In: SILVA, T. T. (Org.). Identidade e diferença: a perspectiva dos estudos culturais. 3. ed. Petrópolis, RJ: Vozes, 2000. p. 73-102.

VOLERY, Thierry. Ethnic entrepreneurship: a theoretical framework. In: DANA, L.-P. (Ed.). Handbook of research on ethnic minority entrepreneurship: a co-evolutionary view on resource management. Cheltenham, UK: Edward Elgar Publishing, 2007. p. 30-41.

WALDINGER, R. The making of an immigrant niche. International Migration Review, v. 28, n. 1, p. 3-28, 1994.

WALDINGER, R.; ALDRICH, H.; WARD, R. Opportunities, group characteristics and strategies. In: WALDINGER, R.; ALDRICH, H.; WARD, R. (Ed.). Ethnic entrepreneurs: immigrant business in industrial societies. London: Sage, 1990. p. 13-48.

WALDINGER, R.; MCEVOY, D.; ALDRICH, H. Spatial dimensions of opportunity structures. In: WALDINGER, R.; ALDRICH, H.; WARD, R. (Ed.). Ethnic entrepreneurs: immigrant business in industrial societies. London: Sage, 1990. p. 106-30.

WEBER, M. A ética protestante e o espírito do capitalismo. São Paulo: Martin Claret, 2002.

WEBER, M. Classe, status e partido. In: VELHO, O. et al. (Org.). Estrutura de classes e estratificação social. 9. ed. Rio de Janeiro: Zahar, 1981. p. 61-83.

ZEN, A. C.; FRACASSO, E. M. Quem é o empreendedor? As implicações de três revoluções tecnológicas na construção do termo empreendedor. Revista de Administração Mackenzie, São Paulo, v. 9, n. 8, p. 135-50, nov./dez. 2008.

\section{Sobre as autoras:}

Laura Aparecida Santos Gomes: Doutoranda (Bolsista CAPES) e mestre pelo Programa de Pós-Graduação em Desenvolvimento Local em Contexto de Territorialidade, pela Universidade Católica Dom Bosco (UCDB). Administradora. E-mail: professoralauragomes@gmail.com, Orcid: http://orcid.org/0000-0002-2477-9982

Cleonice Alexandre Le Bourlegat: Doutora em Geografia (Desenvolvimento Regional) pela Universidade Estadual Paulista (UNESP), Presidente Prudente. Mestre em Geografia (Geografia Humana-Urbana) pela Universidade de São Paulo (USP). Graduada em Geografia pela UNESP. Docente e pesquisadora no Mestrado e Doutorado em Desenvolvimento Local na Universidade Católica Dom Bosco (UCDB). Diretora acadêmica e docente do Master Internacional Erasmus Mundus (STeDe), oferecido pelo consórcio entre a Universidade de Pádua/Itália, Universidade Sorbonne Paris 1, Universidade de Leuven/Bélgica e UCDB/Brasil. Tem exercido a função de professora bolsista da União Europeia na Universidade Paris 1 Panthéon-Sorbonne desde 2013. Pesquisadora da Rede de Pesquisa em Sistemas Produtivos e Inovativos Locais (RedeSist-UFRJ) e integrante do Instituto Histórico e Geográfico de Mato Grosso do Sul (titular). Diretora do Conselho Científico e de Ética do Programa Economia Solidária Sustentável na América do Sul (ESSAS). E-mail: clebourlegat@ucdb.br, Orcid: http://orcid.org/0000-0003-0814-0334 